\title{
DOCUMENTO
}

\section{Relação da Tomada da Colônia do Sacramento}

\author{
Moacyr Flores
}

O folheto Relação do Sitio e tomada da Colônia, de autor anônimo, foi editado em Lima e em Madri, em 1705. Rafael Schiaffino publicou em 1929 uma edição fac-similar do folheto, levantando a hipótese de que o autor seria o governador Alonso del Valle Inclán, que teria feito a relação sob forma de diário da campanha bélica.

Com a guerra de sucessão da coroa espanhola, envolvendo Portugal e Espanha, tratou Sebastião da Veiga, governador da Colônia do Sacramento, de buscar auxílio no Rio de Janeiro. O vice-rei do Peru ordenou o assédio à Colônia com espanhóis e 4.000 índios das reduções jesuíticas, comandados por quatro caciques e com quatro cirurgiões jesuítas.

Os espanhóis, sob o comando do sargento-mor Baltasar Garcia sitiaram a Colônia, com uma esquadrilha de pequenos navios na baia. Os índios e os espanhóis bloquearam a praça portuguesa por terra. Os sitiados contaram com o auxílio de índios charruas, chamados de infiéis, que receberam armas para atacarem os estabelecimentos missioneiros e trazerem gado para a Colônia. $\mathrm{O}$ cerco durou seis meses, porque os espanhóis não conseguindo invadir o reduto, resolveram vencer os portugueses pela fome. Os navios do Rio de Janeiro vieram evacuar os defensores da Colônia, que antes de se retirarem queimaram as casas e as fortificações. Carregaram para bordo das embarcações seus objetos de valor, santos e alfaias da igreja, romperam o cerco entre os pequenos navios inimigos, levando os portugueses em segurança para o Rio de Janeiro.

O documento relata os acontecimentos desde agosto de 1704 , quando da preparação do exército que faria o assédio, até 17 de março de 1705, quando os portugueses escaparam do cerco.

Estudos Ibero-Americanos. PUCRS, v. XXIII, n. 1, p. 165-174, junho, 1997 
Ao traduzir o texto original em espanhol, procurei manter em português a linguagem da época, mudando algumas pontuações, abrindo parágrafos e colocando às vezes as orações em ordem direta, sem alterar o sentido, para uma melhor compreensão do texto.

RELAÇÃO DO SíTIO, tomada e desalojamento da Colônia, chamada de Sacramento, em que se achavam os portugueses desde o ano 1680, no Rio da Prata, à vista das Ilhas de $\mathrm{S}$. Gabriel.

Achando-se o Mestre de Campo D. Alonso Juan de Valdez Inclán, governador e capitão general de Buenos Aires, Províncias do Rio da Prata, com ordens de atacar a Colônia do Sacramento, Praça que ocupavam os portugueses em uma ponta de terra, que faz a costa e forma península, à vista das ilhas de São Gabriel, despovoadas no dito Rio da Prata, dispus logo remeter os que vinham para os governadores de Tucuman e Paraguai e ao superior das Missões da Companhia de Jesus, solicitando socorros de gente, tanto de espanhóis como de índios; e respondeu ao excelentíssimo senhor Conde da Monclova, vice-rei do Peru, em carta de 20 de junho do ano passado de 1704, que a recebeu em 8 de setembro, prestando conta que estava pronto para sitiar e atacar a dita praça.

No presídio de Buenos Aires, se achava o governador com 821 praças de soldados, inclusas as de oficiais maiores e menores. De milicianos se contavam outros 600 espanhóis e 30 entre índios, negros e mulatos. Das cidades de Santa Fé e de Corrientes, que são de sua jurisdição, esperava 300 espanhóis, como igual número da cidade de Córdova do Tucuman, vizinhos e outros milicianos. Das Missões da Companhia de Jesus, havia pedido até 4 mil índios, providenciando armas de fogo, fuzilaria e mosquetaria, espadas, baionetas e lanças para os espanhóis, pois os índios, a cargo dos padres da Companhia, vinham 557 armados com armas de fogo; 1277 com lanças, 133 com espadas e alfanjes e os demais com flechas e pedras.

Para comandante principal e governador dessas tropas, nomeou ao sargento-mor, da Praça de Buenos Aires, D. Baltasar Garcia Roz e por comandante da Cavalaria o capitão de cavalos do presídio de Buenos Aires, Don Martin Mendez, conservando naquela praça competente guarnição, tanto de gente paga como da milícia para seu resguardo e defesa

Tudo tinha que ser transportado a outra do Rio, em distância de oito léguas, para o que se aprestaram uma sumaca, duas lanchas e uma barca que 
havia naquele porto, em que foram transportados as tropas, munições, artilharia, víveres e demais petrechos, que postos na outra margem seriam levadas com dificuldades por rios e pântanos, até colocar-se na Campanha fronteira ao inimigo. Não seria melhor saber o estado em que se achava a Colônia dos portugueses, que guarnição tinha, que petrechos, que artilharia, que víveres? E se acaso tivessem pressentido ao rumor das operações em Buenos Aires.

A Colônia do Sacramento, que estava na costa do Rio da Prata, fundada em terra firme, continente e continua por entre índios infiéis (impenetráveis pela espessura dos matos e grandes distâncias) até o Brasil. Era uma Praça regular de quatro baluartes, com artilharia de bronze e de ferro, fosso profundo e guarnição de 700 homens, povoado construído extramuro próximo ao rio, com casas de terra e palha, um hospital de religiosos de São Francisco e outro dentro da Praça, da Companhia de Jesus. Tinham suas casas de campo e hortas de prazer, haviam roçado grande parte do mato no qual colhiam trigo, milho, lentilha com outros mantimentos. Diz-se que houve um ano em que havendo falta de trigo em Buenos Aires, se ofereceu o Governador da Colônia de vender mais 12 mil fanegas.

Em agosto do ano passado, avisou o governador do Rio de Janeiro, com uma embarcação à Colônia, que Castela havia declarado guerra a Portugal e desde então se viveu com grande risco de que os castelhanos intentassem deitar fora, pela segunda vez, da Colônia, como o fizeram no ano de 1680 , sendo governador de Buenos Aires o general Don Joseph Garro, bem que pela benignidade do Senhor Carlos II (que de Deus goza), se lhes permitiu com certas condições ao portugueses e por não renovar a antiga colocação da linha que se traçou no Orbe pelo Pontífice Alexandre VI, a assim com estes sobressalto, desejavam recolher-se de uma vez ao Rio de Janeiro, ou fortificarse na Colônia, que fosse impraticável desalojá-los.

$\mathrm{E}$ assim dobrando as tarefas, o governador abandonou uma trincheira que havia feito, trabalhando outras mais recuadas até sua Praça, reforçando o terrapleno e tirando novas trincheiras, renovando a estacada nas praias do Rio e pondo sentinelas avançadas, três a quatro légua da Praça e nas Ilhas para observar algum movimento de tropas que viessem de Buenos Aires, preveniuse de abastecimentos para seis meses, esperando que neste prazo não the faltaria socorro em navios do Rio de Janeiro.

O governador de Buenos Aires, impaciente com o afastamento das tropas pela distância dos lugares, pois Córdova dista 130 léguas, de Santa Fé são 80 
de Corrientes, 250. Esperava já com as prevenções e logo que chegaram as de Córdova do Tucuman (porque as outras haviam de marchar pela margem oposta do rio, por estar assim situadas) deu ordem para que saíssem. E a dois de outubro, começaram a mover-se as tropas de Buenos Aires. No dia sétimo receberam da outra margem as de Santa Fé, que armadas e municiadas, thes juntou o sargento-mor Dom Baltasar Garcia Roz a cavalaria e a infantaria que tinha e se pôs em marcha. No dia 11 passou revista geral e contou de cavalaria, 200 homens e 280 de infantaria com 1153 cavalos e 969 mulas.

Continuou sua marcha por terra, levando à vista as lanchas que navegavam pelo rio, e no dia 17 , marchando toda a noite, chegaram às três da manhã à vista da Colônia tocando arma, e a tiro de pistola da muralha, que respondeu com canhonaços e mosquetaria. Este mesmo dia, reconhecida a Praça, se melhorou nosso arraial, pondo diante da Quinta de Alencastro, que se achou abandonada, como a do governador, e outras demolidas, sinal evidente de terem conhecimento de nossa chegada. Aqui colheram os postos sobre a mesma trincheira, que o inimigo havia começada a fazer e abandonado, e com duas Guardas de Cavalaria e uma de Infantaria, ficou cercado o inimigo, de tal forma que ninguém podia sair da Praça sem ser visto.

No dia 19 se apresou uma lancha à vista de sua Praça, que remetida a Buenos Aires, com outras duas apresadas a 8 de outubro, com gente, petrechos correspondentes, serviram para trazer a nosso Campo oito peças de Artilharia e diferentes petrechos. No dia 28 , se rendeu outra lancha à boca do rio de Rosário, servindo para carregar lenha e faxina.

No dia 30 de outubro chegou do Rio de Janeiro um navio à Colônia com 12 canhões, trazia-lhes cal, sal farinha pau, azeite, vinagre, algum dinheiro e 40 homens à Praça, duas peças, munições e pólvora; com notícia de haver uma sumaca do Rio de Janeiro ter feito represálias dos navios ao cargo de D. Carlos Gallo, que se achava naquele porto, tirando-lhe artilharia, gente e carga. Logo que 0 governador de Buenos Aires soube da chegada deste baixel à Colônia, ordenou a D. Joseph de Ibarra Lezcano, capitão-de-mar-e-guerra para que com seu navio de registro Nossa Senhora do Rosário, se aprontasse a todo transe queimar ou apresar o inimigo, para cujo efeito se deitou bando, para os que quisessem embarcar à serviço de Sua Majestade. E do presídio deram 100 homens e outros particulares que se ofereceram, com os quais se pode armar uma sumaca com 40 homens, sob a ordens do capitão Juan Bernardo de Zelaya; uma lancha com 26 homens chefiados por Joseph de Ilumbe; e um bote com 18 homens a cargo de Francisco de Sagastiberri, com outro que 
poucos dias havia chegado do Rio de Janeiro com 18 homens, dos que foram nos navios de Dom Carlos Gallo e tiveram oportunidade de retornar; este se armou com 20 homens, a cargo de Felipe de Zalarain e todos bem apetrechados de pólvora e munições saíram em busca do inimigo.

No dia 10 de novembro teve aviso o governador de Buenos Aires, que tendo começado desde o dia quatro a se levantar terra, estava acabada uma bateria de seis canhões, e a 10, ao amanhecer, começaram a bater a trincheira, baluartes e lugar com grande dano nas casas e alguns na muralha. No dia 11, colocaram outra bateria de quatro canhões à distância de tiro de mosquete da Praça, trabalhando nos ataques até desembocar no fosso. Notou-se que o inimigo disparava com balas miúdas e pedras, e se soube, por meio de um padre da Companhia, que o governador da Praça desejava achar um modo de sair do apuro.

No dia 13 de novembro, o navio do Rosário deu fundo no canal por onde deveria sair o navio português, de nome Teresa. Havia-se combinado o sargento-mor de nosso campo com o chefe de nosso baixel que no dia 23 de novembro, à noite, se tocaria de parte da terra uma arma viva para que, distraídos os inimigos na defesa de sua praça, pudessem nossas embarcações acometer ao navio e apresá-lo, como se executou, porque fazendo-se de terra sinal com uns fuzis, acometeram nossas embarcações ao mesmo tempo a cortar as amarras e anular a artilharia do forte e de três baterias construídas na beira da água, e rebocá-lo, dando e recebendo carga de pedreiros, fuzis e granadas do inimigo, a quem abordaram com singular valor os nossos, atirando as pessoas dentro, onde entenderam abrasar-se vivos, porque o capitão do navio, que com quatro ou cinco homens se escapou num bote para terra, deixou um rastilho aceso no paiol da pólvora, que milagrosamente notaram e apagaram a tempo.

Rendendo-se ao fim ao denodo e intrepidez de nossa gente, o baixel com 33 portugueses prisioneiros, a maioria queimados e feridos e os restantes 55 que fugiram ou morreram, custando-nos sua presa não mais de três homens e 18 feridos, deixando grande glória aos que conseguiram tão arriscada empresa. E na arma, que se tocou em terra, não houve dos espanhóis lastimado algum, mesmo com tão incessante fogo da Praça, como se tivesse 2 mil homens na guarnição, não poderia ser mais.

A primeiro de janeiro de 1705, o sargento-mor D. Baltasar Garcia Roz, realizou uma junta de oficiais e chefes principais, para discutir se concordariam em avança sobre a brecha que haviamos aberto, para reduzir a 
praça ao inimigo, e pelos mais votos se resolveu não estar ainda em condições de avançar, até chegarmos com os ataques na trincheira em que haviamos aberto a brecha. Com esta determinação se deu parte ao governador de Buenos Aires, que julgou de sua obrigação passar o quanto antes ao sítio para incentivar com sua presença a execução das operações.

Passou o governador em pessoa ao sítio em 9 de janeiro, com o mestre de campo D. Estevan de Urizar e Arezpacochaga, da Ordem de Santiago, governador eleito de Tucuman, e 200 homens do presídio. Reconheceu os ataques, o avanço de nossa artilharia e mandou que se acabasse de unir os dois ramais, formando uma Praça de Armas, em que se pusesse uma manga dobrada para socorrer todo as partes; que se formasse nova bateria para atacar um dos redutos das trincheiras do inimigo, continuando-se o ramal começado até um lado e abrindo outro na parte oposta, dirigindo-o ao lugar da brecha aberta, que servisse de caminho coberto.

Tudo se executou e ficou a vinte passos de distância dela, havendo-se encontrado dois fornilhos, que o navio havia colocado, carregados de barriletes de pólvora, transformada em lodo pela vizinhança do rio. E que se fizessem contraminas, para nos defender do inimigo. Passou revista geral e achou 650 espanhóis, fora os enfermos e outros ocupados em diferentes atividades, e 4.000 indios. Substituiu as armas que não estavam em condições, e repartiu-as a quem não as tinham. Nestas operações gastou-se quase todo o mês.

A 31 de janeiro realizou o governador uma Junta de Guerra, dando alento para avançar, se bem lhes parecesse ser em demasia, resolveram que se trabalhasse em prosseguir os ataques e só se continuasse o sítio para rendê-los por fome, pois nos constava estarem com falta de mantimentos.

No primeiro de fevereiro, rompeu o Nombre, disparando nossas quatro baterias contra a Praça, em que se atiraram mais de 300 canhonaços, até as quatro da tarde. Acercando-se os navios sumaca, lanchas e brulotes ao porto, ao meio dia passou toda a gente do Campo por caminho coberto para entrar nos ataques, reforçou-se a guarda da Cavalaria e cobriram os ramais. Baixaram também diferentes companhias de indios em algumas canoas, que estavam na praia, para que todos a um tempo se deixassem ver.

Às quatro da tarde se fez chamada à Praça, e correspondida, saiu o mestre de campo Don Estevam de Urizar y Arezpacochaga com o capitão D. Andrés Gomez de la Quintana e recebidos pelo sargento-mor da Praça disseram-lhe de parte do governador de Buenos Aires, como em termos de boa guerra o exortava, a que lhes entregasse a praça, mediantes honrosas 
capitulações; a que respondeu o português que nosso governador participasse para conferi-las, e que neste interim houvesse cessação de fogo. Mas depois de várias propostas, não admitida de nossa parte, enviaram a nosso governador, que agora lhes concedia capitulação honrada, mas que podia chegar o caso de não poder concedê-la, e reconhecendo que a vontade do português era dilatar o prazo, se lhes intimou que dentro de três dias desocupassem a Praça, saindo com sua guarnição, marchando com todas as honras de guerra; e por não ter Praça própria a que conduzir-se por terra, seriam transportados a Buenos Aires, à paragem que se marcaria à satisfação de todos, onde entregariam por conta todas suas armas de fogo, para restituilas no tempo de sua partida em embarcação ao Rio de Janeiro. O português teve por muito duras estas condições e as limitavam, se era de gosto de nosso governador, que se levassem de refém todos os oficiais da Praça a Buenos Aires, mas nunca permitiriam que levassem suas mulheres e famílias. Depois de outra conferência, o português faria a cessão da Praça, mas não a entrega: mas respondido, que o ponto principal era a possessão que havíamos de tomar a Praça, para embaraçar os termos de cessão, ou entrega, concluiu que não podia capitular, que entregaria a Praça com a condição de morar nela quatro meses, até que viessem do Rio de Janeiro navios que os conduzissem e que de logo nosso governador fosse para Buenos Aires com todos seus oficiais de Guerra. Com esta resolução, respondeu nosso governador que ele havia dado completa satisfação a Deus e ao mundo de seu obrar em termos de boa guerra, e que não esperasse de agora em diante novas capitulações. E assim mandou que se retomasse a guerra como se fez às sete horas da noite.

A 8 de fevereiro se escolheu índios de valor para o avanço, porque todos acometem de tropel, onde vem seus caciques.

A 20, os portugueses incitaram a uns indios infiéis, seus amigos, para hostilizarem as terras de nossos índios tapes, roubando-lhes até 400 cavalos e matando-lhes alguma gente, e outras sentinelas nossas, postas em trechos de oito em oito léguas, até 30 léguas de distância de Montevidéu, que é a paragem que reconhecem os navios que entram no rio da Prata, e onde espera tempo para entrar por qualquer de seus canais. Enviou nosso governador um chefe com duas Companhias de Cavalos com 80 espanhóis e 200 índios tapes, armados com bocas de fogo a castigar os infiéis e afugentá-los, como se executou.

A 5 de março, se soube que em frente de Montevidéu haviam dado fundo quatro navios portugueses, o Guarda Costa Capitânia com 44 canhões, a 
Holandesa Almirante com 30, a Esterlina com 20 e com oito, o patacho Santa Joana, ao todo 200 homens de guarnição, que haviam chegado em 18 dias do Rio de Janeiro. Ordenou logo nosso governador ao capitão-de-mar-e-guerra Dom Joseph de Ybarra, que com seu navio Nossa Senhora do Rosário, de 36 canhões e o navio Santa Teresa, que apresamos dos portugueses, com 16 canhões, de que era capitão-de-mar-e-guerra Juan Bernardo Zelaya e um brulote de fogo, com a guarnição de gente correspondente, e que a armada saísse em perseguição dos quatro batéis inimigos que navegavam até o porto. Assim o executou e acercando-se a tiro de pistola, apresentou-lhes batalha com uma carga cerrada de artilharia, mosquetaria e fuzilaria, a que respondeu o Guarda Costa, seguido de tiros da Holandesa e Santa Joana, ao mesmo tempo que nosso batel Santa Teresa se atracou com a Esterlina durando cerca de quatro horas este combate, em que não se conseguiu a ocasião do brulote de fogo por ter-se desarmado o bote em que haviam de escapar os que pegassem fogo. O inimigo conseguiu penetrar no porto ao abrigo de sua artilharia, mas chegou muito alquebrado e fazendo tanta água que nem pode fazer salva à Praça, mataram-se-lhe três homens e ficaram muitos feridos.

A 6, três lanchas inimigas acometeram uma sumaca nossa, matando a nosso piloto, na primeira carga de pedreiros, com intento de abordá-la, mas foram rechaçados, matando-lhes mais de sua gente de uma lancha que colocamos a pique; e com a morte de alguns da segunda, que com a terceira fugiu para se recolher ao porto.

A 8, fez a Praça salva de fuzilaria, tendo coroado sua muralha e sua trincheira, como se houvesse vindo pessoa de autoridade nos navios.

A 9 de março fez chamada a Praça e correspondida, trouxeram uma carta com assinatura e nome de novo governador e capitão general das Orientais do Rio da Prata e sargento-mor-de-batalha, Dom Pedro Figueiredo Pimentel, que participava ao nosso governador a notícia de sua chegada e de bons desejos de servir-lhe, e logo aparte um protesto que lhe fazia de que se dentro de cinco dias não levantasse suas tropas, que tinha naquele assédio, correria sobre sua responsabilidade os gastos da Fazenda Real, hostilidades, saques e morte que fizessem desde o dia daquela intimação, a que se lhe respondeu com firmeza e liberdade, notando-se com desprezo a arrogância do título de capitão general das Orientais do Rio da Prata.

A 11, um desertor português disse que na Praça morreram de balaços de nossa artilharia, 50 homens, e dez de enfermidades; que nossa primeira bateria que se pôs contra a Praça, fez muito dano nas casas e matou alguma 
gente; que quanto acometeram os índios ao amanhecer, temeram que avançássemos. E quando se fez de nossa parte chamada, alegram-se muita gente, que acharam que era um milagre, desejando que se continuassem os ajustes, e vendo que não concordaram os governadores, se alvorotaram ameaçando que se passariam para nosso campo; que para aquietá-los, disselhes seu governador português que o governador de Buenos Aires queria levar a todos como prisioneiros, e que aos mulatos da Bahia faria escravos; que ao ouvir isto, disseram que queriam lutar até morrer; que a Colônia tinha até sete barris de pólvora. E que no dia 10 de março se deu a última ração para oito dias; e que já se iam embarcando caixas e alfaias dos vizinhos e que neste dia 11 se havia dado ordem que permanecessem embarcadas as pessoas casadas e mulheres, e que se iriam dentro de 15 dias; que dos navios não tiraram pólvora, nem abastecimento, porque só traziam o necessário para conduzi-los; que carne já tinham de sete cavalos, de três machos e de duas mulas que ficaram na Colônia; que na chamada que fizeram no dia 9, o que disse do novo governador D. Pedro Figueiredo, foi tudo ficção e mentira.

No dia 14, nosso governador chegou ao último extremo de avançar, para reconhecer se a Praça estava com menos guarnição, enviou uma arma muito viva, desde o mais próximo ataque, antes de amanhecer, a que respondeu com grande prontidão com todo o fogo da Praça.

Esta noite se passou um soldado de nossa cavalaria ao inimigo, que sem dúvida lhes deu notícias da resolução de nosso Campo, que cheio de pavor e medo não quiseram pedir capitulação, ou porque temiam não fossem favoráveis, ou porque acreditavam que seriam levados prisioneiros a Buenos Aires, ou receavam o furor sangrento do índios tapes, irritados com as hostilidade que lhe fizeram em suas terras os infiéis. Por estes motivos, sem dúvida, viram-se obrigados a fugir na noite de 14 , com tal perturbação e desordem, que deixaram esparramados no embarcadouro seus trastes e alfaias, embarcando nos quatro navios e no dia 15 seguinte, puseram fogo no ranchos que tinham fora e dentro da Praça e às duas da tarde, sairam por último de seu porto duas lanchas e 4 botes, que seguiram aos navios que se colocaram a salvo duas léguas rio a fora, de onde se mantiveram até o dia 17.

Nosso governador mandou uma Companhia de Granadeiros que entrou na Praça e a achou deserta; seguiram quatro magotes da infantaria para ocupar o porto e os redutos das trincheiras, acautelando-se contra as minas, até que no dia seguinte se pudesse reconhecer. 
Deixaram os inimigos na Praça 11 canhões de artilharia, três de bronze e oito de ferro, montados em suas carenas, alguns quintais de ferro, muitos apetrechos, instrumentos de gastadores, muitas balas, granadas e clavinas, muita madeira do Brasil, uma casa pequena de telhas, onde guardavam a pólvora, que a cobiça de três soldados nossos foi buscar com um tição acesso nas mãos, e saltando por desgraça uma chispa, pegou fogo a uns barris de pólvora, que incendiou a dois deles.

A 16, entrou na Praça o governador Dom Alonso Juan de Valdez Inclán, com todos os chefes principais e oficiais, gloriosos de haver desalojado o inimigo, que era seu padrasto nos domínios do Rei Nosso Senhor, e ficava a resolução de demoli-la, para não deixar memória do inimigo, empresa digna de sua constância e valor, correspondente a suas muitas obrigações e militares experiências.

Com licença do Real Governo: em Lima - Na Imprensa Real de Joseph de Contreras. Ano de 1705. 